\title{
Ribonucleic acid content of Burkitt tumour cells
}

\author{
D. H. WRIGHT AND J. C. McALPINE \\ From the Department of Pathology, Makerere University College Medical School, \\ Kampala, Uganda
}

sYNOPSIS Methyl-green-pyronin-Y staining was performed on 57 biopsies of Burkitt's tumour and 62 biopsies from other types of malignant lymphoma. The specificity of the pyronin staining for ribonucleic acid (RNA) was controlled by staining duplicate slides previously digested in ribonuclease. Burkitt's tumour cells have a higher cytoplasmic content of RNA than the cells of most other malignant lymphomas. The results of acridine orange staining of a smaller number of biopsies support these findings.

Intense basophilia of certain cells of the haemopoietic system following staining with Romanowsky dyes has been recognized for many years (White, 1947; Davidson, Leslie, and White, 1948; Rheingold and Wislocki, 1948; Harris and Harris, 1949). Both ultraviolet microspectrophotometry and selective abolition of the basophilia with rubonuclease have indicated that this basophilic substance is ribonucleic acid (Brachet, 1940). Imprint preparations from cases of Burkitt's tumour stained with Romanowsky dyes show intense cytoplasmic basophilia of the tumour cells (Wright, 1963a and b), a feature that differentiates them from most other malignant lymphomas. It was decided therefore to stain biopsy sections from cases of Burkitt's tumour for nucleic acids using a methyl green-pyronin $Y$ method and to compare the results with those obtained on biopsy sections from other types of malignant lymphoma. Imprint preparations from a small number of biopsies of Burkitt's tumour and other malignant lymphomas have also been studied by the acridine orange method for demonstrating nucleic acids.

\section{MATERIALS AND METHODS}

Paraffin sections of formalin-fixed tissue and methylalcohol-fixed imprints of biopsies from cases of Burkitt's tumour were stained by the methyl green-pyronin $Y$ method of Kurnick (1955). The specificity of the pyronin staining for RNA was assessed by staining duplicate slides which had been digested in ribonuclease, $1.0 \mathrm{mg}$. per $\mathrm{ml}$., for 60 minutes at $37^{\circ} \mathrm{C}$. The comparative study of the pyroninophilia of different types of malignant lymphoma was made by staining all the malignant lymphoma biopsies for 1962 and 1963 on which duplicate sections were readily available. Approximately half these biopsies came from Mulago Hospital, Kampala, and half from 'up country' Government and mission hospitals in Uganda and the surrounding territories.

Received for publication 14 October 1965.
The pyroninophilia of the predominant cell type in each type of malignant lymphoma was assessed visually and graded from 0 to +++ , the +++ grading corresponding to the degree of pyroninophilia shown by plasma cells. The grading was made independently by each of us and the results averaged.

Imprints of Burkitt's tumour and of other lymphomas were fixed for five minutcs in Carnoy's fixative and stained in acridine orange. A fluorochrome concentration of $0.01 \%$ in Mcllvaine's citric acid disodium phosphate buffer at $p \mathrm{H} 4.0$ was found to give the best differentiation between RNA and DNA. The stained preparations were mounted in buffer solution and examined by blue light fluorescence using a BG 12 filter and an OG 1 selective eyepiece filter.

\section{RESULTS}

Occasional biopsies showed a diffuse mauve staining of the nucleus and the cytoplasm. This was presumably due to faulty fixation and these cases were discarded from the study.

The intensity of pyroninophilia in 57 cases of Burkitt's tumour and 62 cases of other types of malignant lymphoma are shown in Fig. 1. Although there is considerable overlap, Burkitt tumour cells show a greater degree of pyroninophilia than the cells of lymphocytic lymphomas and histiocytic lymphomas. Half the cases of stem-cell lymphoma showed the same degree of pyroninophilia as Burkitt's tumour.

In keeping with the cytological uniformity of Burkitt's tumour the cytoplasmic pyroninophilia was uniform throughout all the cells in the biopsy (Fig. 2). In contrast, most cases of poorly differentiated lymphocytic lymphoma and most histiocytic lymphomas showed a range of cells with varying intensities of cytoplasmic pyroninophilia. Acridine orange staining was in conformity with these 

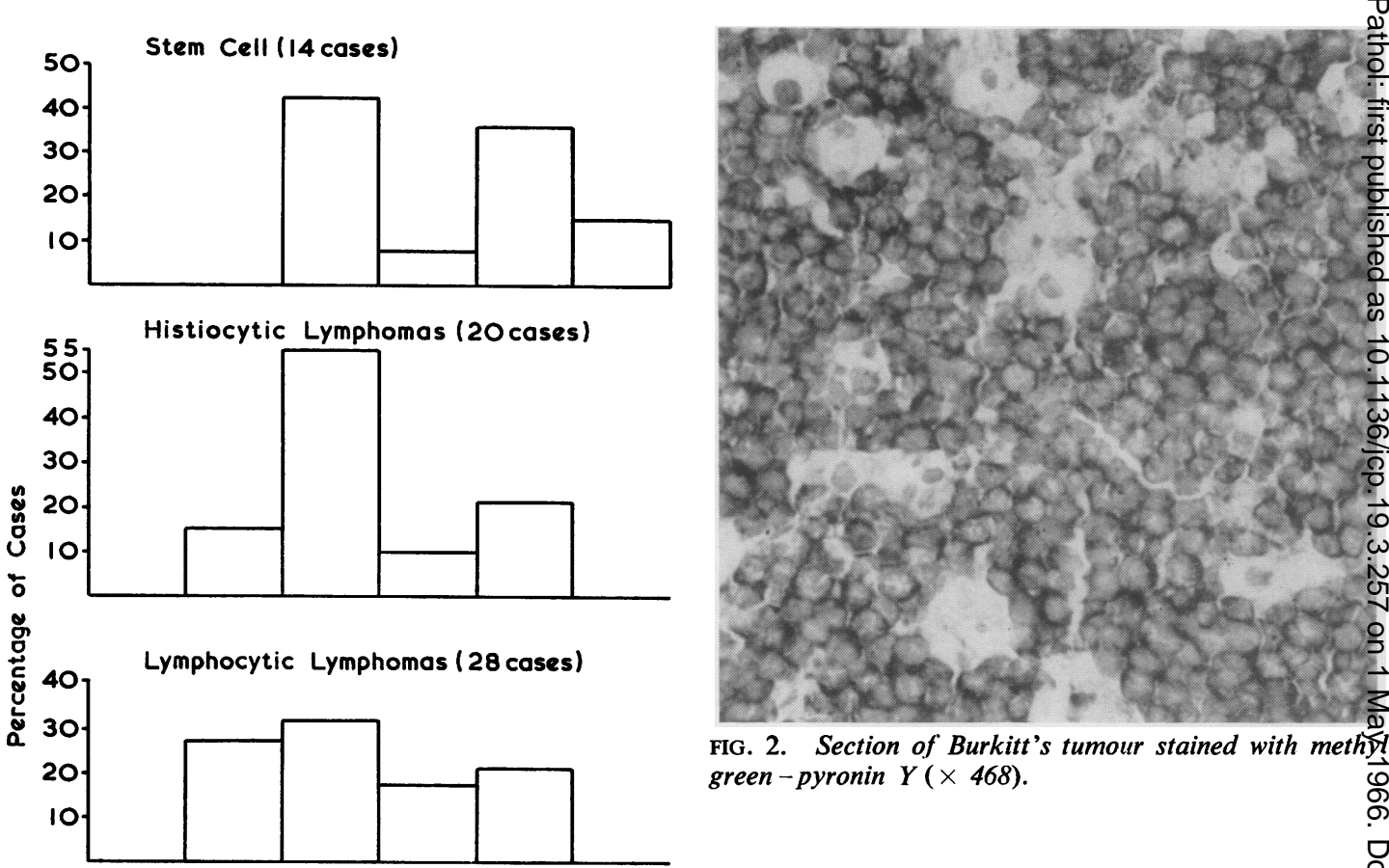

FIG. 2. Section of Burkitt's tumour stained with methyl green-pyronin $Y(\times 468)$.

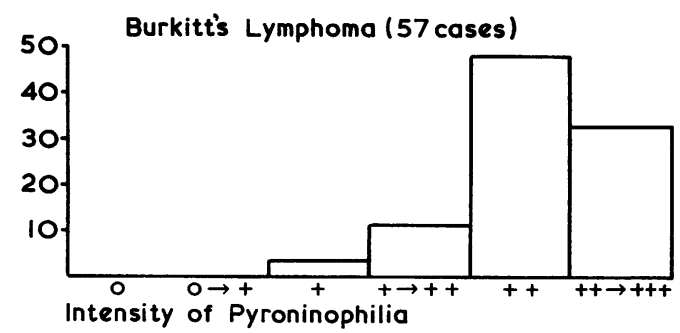

FIG. 1. Intensity of pyroninophilia of Burkitt's tumour cells compared with the cells of other malignant lymphomas.

results. Burkitt's tumour cells stained with acridine orange showed an intense, uniform, flame-red cytoplasmic fluorescence and yellow-green nuclear fluorescence.

The large clear or vacuolated histiocytes that are such a characteristic feature of Burkitt's tumour contained, in addition to whole lymphoid cells, many fragments of pyroninophilic material.

\section{DISCUSSION}

The results obtained with methyl green-pyronin $\mathbf{Y}$ staining confirm that Burkitt tumour cells have a higher cytoplasmic content of ribonucleic acid than the cells of most lymphocytic lymphomas and most histiocytic lymphomas. There is considerable overlap

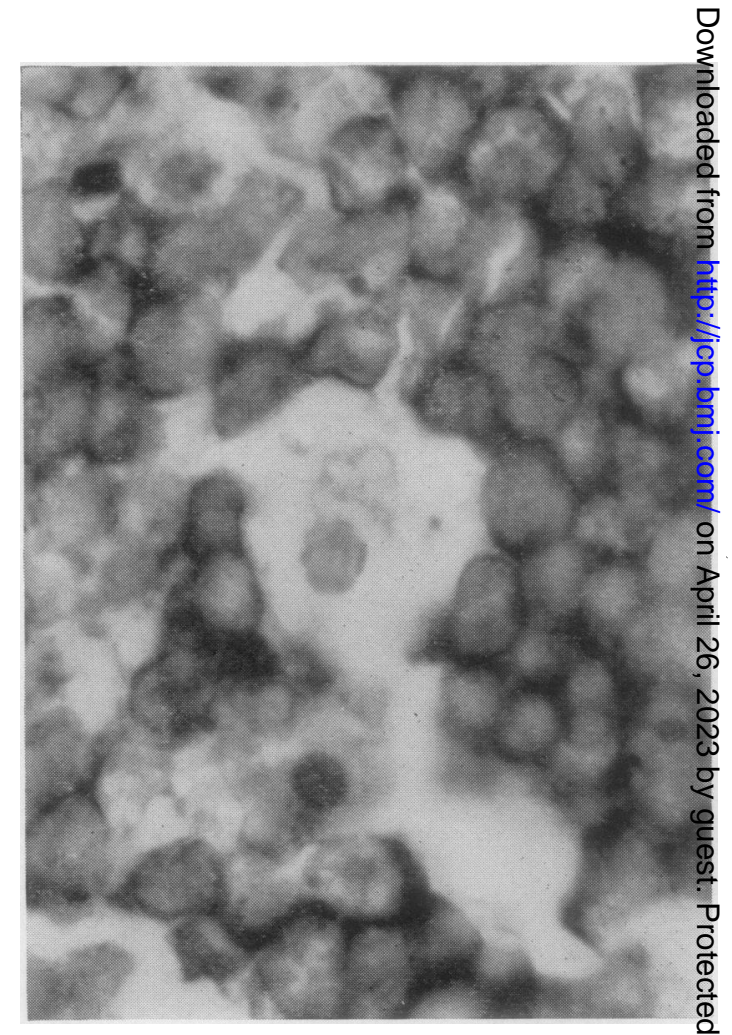

FIG. 3. Section of Burkitt's tumour stained with methot green-pyronin $Y(\times 1,500)$. 


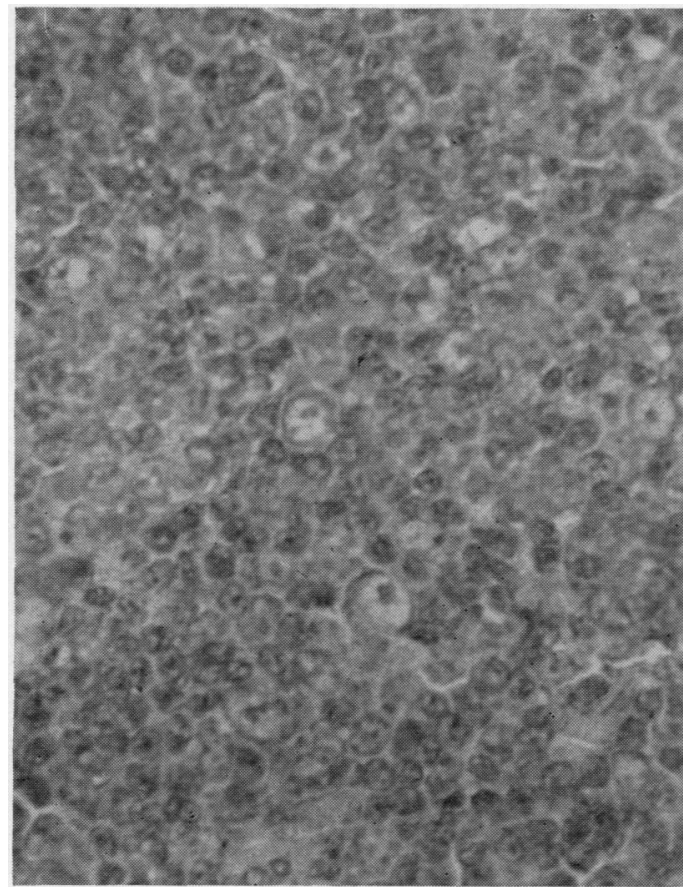

FIG. 4. Section of malignant lymphoma poorly differentiated lymphocytic type (lymphosarcoma) stained with methyl green-pyronin $Y(\times 468)$.

with cases of stem-cell lymphoma but these are usually easily distinguishable from Burkitt's tumour using other cytological criteria. Intense cytoplasmic basophilia has been a constant feature of over 50 Giemsa-stained imprint preparations of fresh biopsies of Burkitt's tumour studied by one of us (D.H.W.). It is probable, therefore, that the occasional low intensity of pyroninophilia obtained in sections of Burkitt's tumour was due to poor fixation of the biopsy rather than to a real deficiency of the ribonucleic acid content of the cells.

A high cytoplasmic content of ribonucleic acid is a feature of protein-secreting cells, as well as of haemopoietic blast cells and many embryonic and tumour cells. Protein-secreting cells have a well developed endoplasmic reticulum fringed with ribonucleoprotein granules (Palade, 1955) whereas blast cells do not have a well-developed endoplasmic reticulum and the ribonucleoprotein granules are scattered freely throughout the cytoplasm (Bernhard and Granboulan, 1960). Electron microscope studies have shown that the cytoplasm of Burkitt tumour cells is rich in ribosomes which occasionally show a tendency towards clumping. The endoplasmic reticulum is poorly developed and most of the ribosomes are free within the cytoplasm (O'Conor, personal communication). Electrophoresis of the serum from cases of Burkitt's tumour has shown no specific protein abnormalities of the type seen in multiple myelomatosis (Martin, personal communication). The high cytoplasmic level of ribonucleic acid in Burkitt tumour cells may be a reflection of the rapid multiplication of these cells and the correspondingly high rate of protein synthesis.

The abundant cytoplasmic ribonucleic acid in Burkitt tumour cells gives an amphophilic staining quality to the cytoplasm of these cells in sections of formalin-fixed material stained with haemotoxylin and eosin. This staining quality, similar to that seen in plasma cells, is best demonstrated in tissue fixed in buffered neutral formalin and is usually absent when acid fixatives have been used. It is one of the histological features used in this department for the diagnosis of Burkitt's tumour. Its intensity and uniformity throughout the biopsy helps to differentiate Burkitt's tumour from other malignant lymphomas and also from retinoblastomas and neuroblastomas which may be confused with Burkitt's tumour clinically.

\section{REFERENCES}

Bernhard, W., and Granboulan, N. (1960). In Ciba Foundation Symposium on Cellular Aspects of Immunity, ed. by G. E. W. Wolstenholme and M. O'Connor, p. 92. Churchill, London. Brachet, J. (1940). C. R. Soc. Biol. (Paris), 133, 88.

Davidson, J. N., Leslie, I., and White, J. C. (1948). J. clin. Path., 60, 1. Harris, T. N., and Harris, S. (1949). J. exp. Med., 90, 169.

Kurnick, N. B. (1955). Stain Technol., 30, 213.

Martin, N. H. (1964). Personal communication.

O'Concr, G. T. (1964). Personal communication.

Palade, G. E. (1955). J. biophys. biochem. Cytol., 1, 59.

Rheingold, J. J., and Wislocki, G. B. (1948). Blood, 3, 641.

White, J. C. (1947). J. clin. Path., 59, 223.

Wright, D. H. (1963a). Brit. J. Cancer, 17, 50.

(1963b). In International Review of Experimental Pathology, edited by G. W. Richter, and M. A. Epstein, vol. 2, p. 97. Academic Press, New York. 